\title{
Marketing Process Reengineering within a Romanian Software Company Focused on the Implementation of a Freelancing Strategy
}

\author{
Adrian Micu ${ }^{1}$, Alexandru Capatina ${ }^{1}$, Angela Eliza Micu ${ }^{2}$ \\ ${ }^{1}$ Dunarea de Jos University of Galati, Galati, Romania; ${ }^{2}$ Faculty of Economic Sciences, Ovidius University of Constanta, Constanta, \\ Romania. \\ Email: mkdradrianmicu@yahoo.com
}

Received November $10^{\text {th }}, 2012$; revised December $8^{\text {th }}, 2012$; accepted December $15^{\text {th }}, 2012$

\begin{abstract}
This paper examines several possibilities regarding the implementation of the marketing process reengineering within a Romanian software company. Specifically, it argues that freelancing implementation in the Competitors Tracking area leads to a better performance of the overall marketing activity, by means of a mathematical model which reveals four situations corresponding to the research hypotheses. According to the variables related to the mathematical model, the marketing tasks are divided in different areas and we highlighted the opportunity to develop a new area-Competitor Tracking through a marketing process reengineering. The results show that reengineering focuses on redesigning the process as a whole in order to achieve the greatest possible benefits to the organization. The driving forces associated to the reengineering will lead improvements by fundamentally rethinking how the Competitor Tracking positions should be fulfilled - through permanent workers or freelancers. The results of our analysis provides a decision-making support for the marketing manager of the software company, leading to a better positioning through Competitive Intelligence techniques, which build and leverage its competitive advantages.
\end{abstract}

Keywords: Software Industry; Marketing Process Reengineering; Freelancing; Competitive Intelligence

\section{Introduction}

Nowadays the freelancing concept is approached through a series of research articles, but only from the freelancers' points of view. According to Wikipedia, a freelancer is somebody who is self-employed and is not committed to a particular employer long term. Taking into consideration the technological innovations and changes in our knowledge society, we can notice an increase of the peoples' intentions reflecting their wishes to work as freelancers. Moreover, there are public debates on the freelancer concept, but we observed few empirical studies focused on freelancing strategies in terms of HR process, which quantify the impact of this approach on the organisational performance.

Several studies have looked into the role of freelancers in the HR strategies of the companies. The organizational employment practices are closely associated with HR management orientation towards contract freelance workers or permanent employees [1]. While organizations will continue to be the predominant consumers and suppliers of global talent, there is an interesting trend in the use of freelance outsourcing. With freelance out- sourcing, individuals offer their talents globally, primarily through freelance websites [2]. Freelancers still have the independent causal power to shape the ways of restructuring the activities within an organisation, by choosing how to act within the "room for manoeuvre" they have available [3].

Human resource professionals may face difficulty in meeting the needs of stakeholders for an evidence-based evaluation that demonstrates coaching contributes to organizational performance [4]. In this way, a freelancing initiative could be considered as a solution to value the expertise of external HR consultants.

Previous literature of marketing process reengineering focused primarily on the perspective considering that marketing is first and foremost a philosophy of doing business which puts customer satisfaction at the core of the decision-making process; in such a context, it appears to generate for marketers the opportunity to ensure a genuinely market-oriented business strategy [5]. Other relevant studies in this field emphasize marketing process reengineering role within business cycle time reduction through the implementation of information systems in "real-time" processes [6] and its potential to create more 
flexible, team-oriented, coordinative, and communication-based work capability in marketing departments [7].

The information related to a marketing reengineering process outcomes influence a company performance through three important organizational capabilities: customer, process, and performance management [8].

Due to increasing competition, decreasing innovation cycles and increasing technology complexity, the achievement of a software company's success has lately received renewed attention [9]. In this context, we consider that a prior attention should be addressed to Competitor Tracking activities. Through monitoring environment and tracking competitors continuously, the employees specialized in competitive intelligence techniques could readily discern some critical factors of environment changes that are enterprise-related internally and externally, so as to identify early-warning signals of potential risks and additional risks [10].

This paper aims at revealing a marketing process reengineering project implemented within a software company and to assess in a comparative manner the performances associated to the competitive tracking tasks, which could be fulfilled by permanent employees or freelancers.

The article is organized as follows: firstly, we presented the main contributions related to freelancing and marketing process reengineering. Then, the research methodology focused on the design of four hypotheses is outlined. Subsequently, the results of a mathematical model which allows the hypotheses testing process are discussed and the advantages of the PathMaker software implementation-support for marketing process reengineering within the analyzed companies are highlighted. Finally, the managerial implications and further research agenda are emphasized.

\section{Research Methodology}

The decision regarding the implementation of the marketing process reengineering within the software company, considered for the case study, emerges as a solution consciously chosen by the marketing manager from several possible variants, using a simulation scenario, in order to improve the overall performance of the Marketing department.

The four hypotheses that will be tested through a mathematical modelling process are the following:

$\mathbf{H}_{1}$ : The situation with two permanent employees in Competitor Tracking area of the software company's Marketing Department is the optimal solution from the marketing performance point of view.

$\mathbf{H}_{2}$ : The situation with one permanent employee in Competitor Tracking area of the software company's
Marketing Department is the optimal solution from the marketing performance point of view.

$\mathbf{H}_{3}$ : The situation with one permanent employee and one freelancer in Competitor Tracking area of the software company's Marketing Department is the optimal solution from the marketing performance point of view.

$\mathbf{H}_{4}$ : The situation with two freelancers in Competitor Tracking area of the software company's Marketing Department is the optimal solution from the marketing performance point of view.

\section{Mathematical Modelling of the Benefits Related to the Freelancing Implementation in the Competitors Tracking Area}

The mathematical pattern that we developed intends to emphasize an approach that represents the high benefits the marketing department the software company considered for the case study can get through freelancing implementation in the Competitors Tracking area. A mathematical modelling was achieved using the random simulation.

The marketing department of the company, composed by 11 employees assigned in different areas, encountered four major tasks, by taking into consideration the opportunity to hire one or two employees for a new areaCompetitor Tracking. Using economic-mathematical calculations, successive simulations were achieved for these major tasks, using the following symbols:

$N=$ number of employees in marketing department;

$x=$ number of employees that form the team, where $x \epsilon$ $\{0,1\}$;

$K=$ total number of employees working on task " $i$ ";

Pi $x i=$ value achieved by employee $x$ working on task “i”;

$P(M K)=$ marketing department performance;

$E(P(M K))=$ expected performance;

$P i\left(x i^{k}\right)=$ performance mean based on $\mathrm{k}$ tasks.

Using these symbols, we took into account the fact that marketing department performance is a three-variable dependent value as follows:

$$
\begin{gathered}
P(M K)=f(N, K, P i x i) \\
P(M K)=\frac{\sum_{i=1}^{N} P_{i}\left(x i^{k}\right)}{N} \\
P\left(x i^{k}\right)=\frac{\sum_{i=1}^{N} P_{i}\left(x i^{k}\right)}{N}
\end{gathered}
$$

These empirical formulas were applied in four simulation scenarios, in order to determine the optimal alterna- 
tive associated to the marketing process reengineering initiative.

In the first situation, we revealed the situation in which the company didn't take into consideration the freelancing strategy, using two permanent employees for Competitor Tracking activities (Table 1).

$$
\begin{gathered}
P i x i=\frac{\sum_{i=1}^{K} P i(x i)}{K} \\
P i x i=\frac{0.958+0.437+0.563+0.801+0.605+0.503+0.432+0+0.521+0+0.721+0+0}{9} \\
P i x i=0.61 \\
P(M K)=\frac{\sum_{i=1}^{N} P_{i}\left(x i^{k}\right)}{N} \\
P(M K)=\frac{0.958+0.437+0.563+0.801+0.605+0.503+0.432+0+0.521+0+0.721+0+0}{13} \\
P(M K)=0.42
\end{gathered}
$$

In the second situation, the software company's marketing manager was not still interested in the application of freelancing strategy, but he assigns only permanent

\begin{tabular}{|c|c|c|c|}
\hline Marketing department employees & Assigned value $^{*}$ & Coefficient & Acquired value (1) \\
\hline $\mathrm{X} 1$ : Marketing manager & 1 & $P 1 \times 1$ & 0.958 \\
\hline$x 2$ : Competitor Tracking team leader & 1 & $P 1 \times 2$ & 0.437 \\
\hline x3: Marketing database Administrator & 1 & $P 1 \times 3$ & 0.563 \\
\hline$x 4$ : Advertising team leader & 1 & $P 1 \times 4$ & 0.801 \\
\hline$x 5$ : IT team leader & 1 & $P 1 \times 5$ & 0.605 \\
\hline x6: Competitor Tracking employee 1 & 1 & $P 1 \times 6$ & 0.503 \\
\hline x7: Competitor Tracking employee 2 & 1 & $P 1 \times 7$ & 0.432 \\
\hline$x 8:$ PR employee 1 & 0 & $P 1 \times 8$ & 0 \\
\hline$x 9$ : PR employee 2 & 1 & $P 1 \times 9$ & 0.521 \\
\hline$x 10$ : Advertising employee 1 & 0 & $P 1 \times 10$ & 0 \\
\hline$x 11$ : Advertising employee 2 & 1 & $P 1 \times 11$ & 0.721 \\
\hline$x 12$ : IT employee 1 (web marketing) & 0 & $P 1 \times 12$ & 0 \\
\hline \multirow[t]{2}{*}{$x 13:$ IT employee 2 (integration) } & 0 & $P 1 \times 13$ & 0 \\
\hline & & & 5.541 \\
\hline
\end{tabular}
employees for Competitor Tracking activities (Table 2).

$$
P j x i=\frac{\sum_{j=1}^{K} P i(x i)}{K}
$$

where $P j=$ arithmetical mean of employee $x$ performance for previous task and current task.

Table 1. Simulation of the situation with two permanent employees in Competitor Tracking area.

\footnotetext{
"Assigned value $=1$ means that employee " $x$ " works on task " $i$ "; Assigned value $=0$ means that employee " $x$ " does not work on task " $i$ ".
} 
Table 2. Simulation of the situation with one permanent employee in Competitor Tracking area.

\begin{tabular}{|c|c|c|c|c|}
\hline Marketing department employees & Assigned value & Coefficient & $\begin{array}{c}\text { Acquired } \\
\text { value (2) }\end{array}$ & Arithmetical mean $(1)+(2)$ \\
\hline$x 1$ : Marketing manager & 1 & $P 2 \times 1$ & 0.947 & 0.952 \\
\hline$x 2$ : Competitor Tracking team leader & 1 & $P 2 \times 2$ & 0.503 & 0.470 \\
\hline x3: Marketing database Administrator & 1 & $P 2 \times 3$ & 0.510 & 0.536 \\
\hline$x 4$ : Advertising team leader & 1 & $P 2 \times 4$ & 0.643 & 0.722 \\
\hline x5: IT team leader & 1 & $P 2 \times 5$ & 0.645 & 0.625 \\
\hline x6: Competitor Tracking employee 1 & 1 & $P 2 \times 6$ & 0.523 & 0.513 \\
\hline x7: Competitor Tracking employee 2 & $\mathbf{0}$ & $P 2 \times 7$ & $\mathbf{0}$ & 0.216 \\
\hline$x 8:$ PR employee 1 & 0 & $P 2 \times 8$ & 0 & 0 \\
\hline$x 9$ : PR employee 2 & 1 & $P 2 \times 9$ & 0.489 & 0.505 \\
\hline$x 10$ : Advertising employee 1 & 0 & $P 2 \times 10$ & 0 & 0 \\
\hline$x 11$ : Advertising employee 2 & 1 & $P 2 \times 11$ & 0.542 & 0.631 \\
\hline$x 12:$ IT employee 1 (web/marketing) & 0 & $P 2 \times 12$ & 0 & 0 \\
\hline \multirow[t]{2}{*}{$x 13:$ IT employee 2 (integration) } & 0 & $P 2 \times 13$ & 0 & 0 \\
\hline & & & 4.802 & 5.171 \\
\hline
\end{tabular}

$$
\begin{gathered}
P j x i=\frac{\frac{P 1 x 1+P 2 \times 1}{2}+\frac{P 1 \times 2+P 2 \times 2}{2}+\frac{P 1 \times 3+P 2 \times 3}{2}+\cdots+\frac{P 1 \times 12+P 2 \times 12}{2}+\frac{P 1 \times 13+P 2 \times 13}{2}}{8} \\
P j x i=\frac{0.952+0.470+0.536+0.722+0.625+0.513+0.216+0+0.505+0+0.631+0+0}{8} \\
P j \times i=0.64 \\
P(M K)=\frac{0.952+0.470+0.536+0.722+0.625+0.513+0.216+0+0.505+0+0.631+0+0}{13} \\
P(M K)=0.39
\end{gathered}
$$

In the third situation, the software company's market- one permanent employee and one freelancer for Coming manager took into consideration the situation with petitor Tracking activities (Table 3).

$$
\begin{gathered}
P j x i=\frac{\frac{P 1 x 1+P 2 x 1+P 3 x 1}{3}+\frac{P 1 x 2+P 2 x 2+P 3 x 2}{3}+\frac{P 1 \times 3+P 2 \times 3+P 3 x 3}{3}+\cdots+\frac{P 1 x 13+P 2 \times 13+P 3 \times 13}{3}}{8} \\
P j x i=\frac{0.955+0.561+0.540+0.740+0.622+0.512+0.368+0+0.507+0+0.421+0+0}{8} \\
P j x i=0.65 \\
P(M K)=\frac{0.955+0.561+0.540+0.740+0.622+0.512+0.368+0+0.507+0+0.421+0+0}{13} \\
P(M K)=0.41
\end{gathered}
$$


Table 3. Simulation of the situation with one permanent employee and one freelancer in Competitor Tracking area.

\begin{tabular}{|c|c|c|c|c|}
\hline Marketing department employees & $\begin{array}{c}\text { Assigned } \\
\text { value }\end{array}$ & Coefficient & $\begin{array}{c}\text { Acquired value } \\
\text { (3) }\end{array}$ & $\begin{array}{l}\text { Arithmetical mean } \\
(1)+(2)+(3)\end{array}$ \\
\hline$x 1$ : Marketing manager & 1 & $P 3 \times 1$ & 0.961 & 0.955 \\
\hline$x 2$ : Competitor Tracking team leader & 1 & $P 3 \times 2$ & 0.743 & 0.561 \\
\hline x3: Marketing database Administrator & 1 & $P 3 \times 3$ & 0.549 & 0.540 \\
\hline$x 4$ : Advertising team leader & 1 & $P 3 \times 4$ & 0.776 & 0.740 \\
\hline x5: IT team leader & 1 & $P 3 \times 5$ & 0.618 & 0.622 \\
\hline x6: Competitor Tracking employee 1 & 1 & $P 3 \times 6$ & 0.512 & 0.512 \\
\hline Z2: Competitor Tracking freelancer 2 & 1 & $P 3 \times 7$ & 0.672 & 0.368 \\
\hline x8: PR employee 1 & 0 & $P 3 \times 8$ & 0 & 0 \\
\hline$x 9$ : PR employee 2 & 1 & $P 3 \times 9$ & 0.513 & 0.507 \\
\hline$x 10$ : Advertising employee 1 & 0 & $P 3 \times 10$ & 0 & 0 \\
\hline$x 11$ : Advertising employee 2 & 0 & $P 3 \times 11$ & 0 & 0.421 \\
\hline$x 12:$ IT employee 1 (web marketing) & 0 & $P 3 \times 12$ & 0 & 0 \\
\hline \multirow[t]{2}{*}{$x 13:$ IT employee 2 (integration) } & 0 & $P 3 \times 13$ & 0 & 0 \\
\hline & & & 5.344 & 5.392 \\
\hline
\end{tabular}

In the fourth situation, the software company's marketing manager simulated the overall marketing process reengineering situation, which involves two freelancers for Competitor Tracking activities (Table 4).

$$
\begin{gathered}
P j x i=\frac{0.959+0.608+0.574+0.749+0.622+0.580+0.444+0+0.536+0+0.315+0+0}{8} \\
P j x i=0.67 \\
P(M K)=\frac{0.959+0.608+0.574+0.749+0.622+0.580+0.444+0+0.536+0+0.315+0+0}{13} \\
P(M K)=0.41
\end{gathered}
$$

The mathematical modelling of marketing department HR performance revealed the four hypotheses test results; the simulation achieved on the 4 major tasks and we determined the performance of the whole marketing department, acquired for both $N=$ marketing employee number and $K=$ total number of employees working on task " $i$ ". The fourth situation reached the highest value (0.67), thus demonstrating that the marketing process reengineering focused on the introduction of two freelancers in Competitor Tracking area is the optimal choice.

\section{Implementation of PATHMAKER 6.1 in the Marketing Process Reengineering Within the Software Company}

The advantages of the PATHMAKER 6.1 software use as support of the marketing process reengineering within the software company considered for the case study will be emphasized in the context of freelancing initiative implementation in the company's marketing department.

Project Pathway tool allows the configuration of the marketing process reengineering activities involved in our analysis, the emphasis of the progress in what concern the tasks' accomplishment and the planning of virtual meetings.

We emphasized in Figure 1 the customized activities of the marketing process reengineering, implemented within the software company, by means of specific tools such as brainstorming tool, cause and effect tool, consensus builder, data analyst tool and force field analysis.

We also revealed the opportunity to effectively manage the creative process of ideas storming within the virtual meetings, using the Brainstorm/Affinity Diagram Tool. We applied "Drag and Drop" technique, in order to 
Focused on the Implementation of a Freelancing Strategy

Table 4. Simulation of the situation with two freelancers in Competitor Tracking area.

\begin{tabular}{|c|c|c|c|c|}
\hline Marketing department employees & $\begin{array}{l}\text { Assigned } \\
\text { value }\end{array}$ & Coefficient & $\begin{array}{l}\text { Acquired } \\
\text { value (4) }\end{array}$ & $\begin{array}{l}\text { Arithmetical mean } \\
(1)+(2)+(3)+(4)\end{array}$ \\
\hline$x 1$ : Marketing manager & 1 & $P 4 \times 1$ & 0.972 & 0.959 \\
\hline$x 2$ : Competitor Tracking team leader & 1 & $P 4 \times 2$ & 0.752 & 0.608 \\
\hline x3: Marketing database Administrator & 1 & $P 4 \times 3$ & 0.676 & 0.574 \\
\hline$x 4$ : Advertising team leader & 1 & $P 4 \times 4$ & 0.777 & 0.749 \\
\hline$x 5$ : IT team leader & 1 & $P 4 \times 5$ & 0.622 & 0.622 \\
\hline Z1: Competitor Tracking freelancer 1 & 1 & $P 4 \times 6$ & 0.785 & 0.580 \\
\hline Z2: Competitor Tracking freelancer 2 & 1 & $\mathbf{P 4} \times 7$ & 0.674 & 0.444 \\
\hline$x 8:$ PR employee 1 & 0 & $P 4 \times 8$ & 0 & 0 \\
\hline$x 9:$ PR employee 2 & 1 & $P 4 \times 9$ & 0.623 & 0.536 \\
\hline$x 10$ : Advertising employee 1 & 0 & $P 4 \times 10$ & 0 & 0 \\
\hline$x 11$ : Advertising employee 2 & 0 & $P 4 \times 11$ & 0 & 0.315 \\
\hline$x 12$ : IT employee 1 (web marketing) & 0 & $P 4 \times 12$ & 0 & 0 \\
\hline \multirow[t]{2}{*}{$x 13$ : IT employee 2 (integration) } & 0 & $P 4 \times 13$ & 0 & 0 \\
\hline & & & 5.881 & \\
\hline
\end{tabular}

11. PathMaker - [C:Documents and SettingsUserWy DocumentsWy PathMaker Files ProjectsLocalProjec 淕 File Edit View Pathway Collaborate Window Help



\begin{tabular}{|c|c|c|c|c|c|c|c|}
\hline \multicolumn{4}{|c|}{ †Project Pathway } & i Project Information & \multirow[t]{2}{*}{ Tean Members } & Action Items & \multirow[t]{2}{*}{ Diser Discussion History } \\
\hline &  & Open & \multicolumn{3}{|c|}{ Description } & & \\
\hline 1 & Г & & \multicolumn{5}{|c|}{$\begin{array}{l}\text { Evaluation of the freelancing implementation impact on the marketing performance } \\
\text { of the software company }\end{array}$} \\
\hline 2 & $\Gamma$ & 隐 & \multicolumn{5}{|c|}{ Brainstorming: What are the goals of the marketing process reengineering? } \\
\hline 3 & $\Gamma$ & 䗆 & \multicolumn{5}{|c|}{ Cause \& Effect Tool: Map the results of the brainstorming session } \\
\hline 4 & $\Gamma$ & & \multicolumn{5}{|c|}{$\begin{array}{l}\text { Design of Competitive Intelligence tools on short, medium and long term for the } \\
\text { software company }\end{array}$} \\
\hline 5 & $\Gamma$ & 回 & \multicolumn{5}{|c|}{ Development of a SWOT analysis } \\
\hline 6 & $\Gamma$ & 极 & \multicolumn{5}{|c|}{$\begin{array}{l}\text { Brainstorming: What should be the organisation's objectives in terms of competitors' } \\
\text { tracking? }\end{array}$} \\
\hline 7 & $\Gamma$ & 蛞 & \multicolumn{5}{|c|}{ Cause \& Effect Tool: Map the fundamental and derived objectives } \\
\hline 8 & $\Gamma$ & 金 & \multicolumn{5}{|c|}{ Consensus Builder: Which freelancers shall we approach in the marketing department? } \\
\hline 9 & $\Gamma$ & $\underline{\underline{x}}$ & \multicolumn{5}{|c|}{$\begin{array}{l}\text { Gather and analyze pertinent data in view to determine the freelancers' performance in } \\
\text { competitors tracking activities }\end{array}$} \\
\hline 10 & $\Gamma$ & 䍂 & \multicolumn{5}{|c|}{$\begin{array}{l}\text { Brainstorming: What are the key succes factors for the development of a differentiation } \\
\text { strategy? }\end{array}$} \\
\hline 11 & $\Gamma$ & 幽 & \multicolumn{5}{|c|}{ Data Analyst Tool: Design of a monitoring system focused on key succes factors } \\
\hline 12 & $\Gamma$ & & \multicolumn{5}{|c|}{ Planning the objectives for marketing process reengineering post-implementation } \\
\hline 13 & $\Gamma$ & 吅 & \multicolumn{5}{|c|}{ Cause \& Effect Tool: Dissemination of objectives to the level of stakeholders } \\
\hline 14 & $\Gamma$ & stis & \multicolumn{5}{|c|}{ Improvement of the competitive position of the company } \\
\hline 15 & $\Gamma$ & $\underline{x}$ & \multicolumn{5}{|c|}{$\begin{array}{l}\text { st Tool: Evaluation of the marketing proce } \\
\text { Benchmarking techniques }\end{array}$} \\
\hline
\end{tabular}

Figure 1. Implementation of the Project Pathway in the marketing process reengineering within the software company. 
sort the ideas in clusters by means of KJ (Kawakita Jiro) diagrams.

Brainstorming sessions played an important role in the planning and implementation of reengineering project; in this way, we considered ten ideas developed in such a session by the company's stakeholders (Figure 2).

The discussions with the software company's manager regarding the efficient use of the Meeting Tool outlined the opportunity to view in real time the information from the Project Pathway reports; in this way, the reports from different sessions developed during the marketing process reengineering project were registered and submitted online to the software company headquarter based in US.

Consensus Builder tool played an important role in the process of choosing the most valuable ideas shared within brainstorming sessions developed during the marketing process reengineering, determining the consensus in the company's reengineering project team. The matrix provided by this tool allows the implementation of multivoting system and implicitly facilitates the decision making process.

Data Analyst Tools facilitated the design of graphs, which reveal the results of the application of marketing process reengineering project.

Cause-effect analyses, represented by Ishikawa diagrams, encouraged the creativity by the use of the brainstorming process and provide a visual image of a problem and the potential categories of causes. The selection of the most valuable ideas discussed during the brainstorming session involved such a cause-effect approach, focused on the issues revealed in Figure 3. The correlation between the reengineering tools (brainstorming sessions and cause-effect analyses-Ishikawa diagrams) reinforced the implication of the team project members. The analysis of relevant data allowed better decision making and mitigates the risk of decisions based on personal opinions.

The design of the Force Field pattern in view to improve the competitive position of the software company after the implementation of the marketing process reengineering took into consideration the following issue: every change involves two opposite attitudes: driving forces and restraining forces, which are represented in a template provided by PATHMAKER 6.1 software as arrows (Figure 4).

The quantification of the forces by the automatic assignments of a score provided by PATHMAKER 6.1 software allowed the assessment of the effect determined by the impact of driving and restraining forces. In this particular case, we observed a superior sum of driving forces than the sum of restraining forces, leading to the achievement of the central issue addressed in the marketing process reengineering.

The possibility to report the PATHMAKER 6.1 software templates in Office applications led to an increase of its use at the global level, being an efficient support of reengineering projects management.

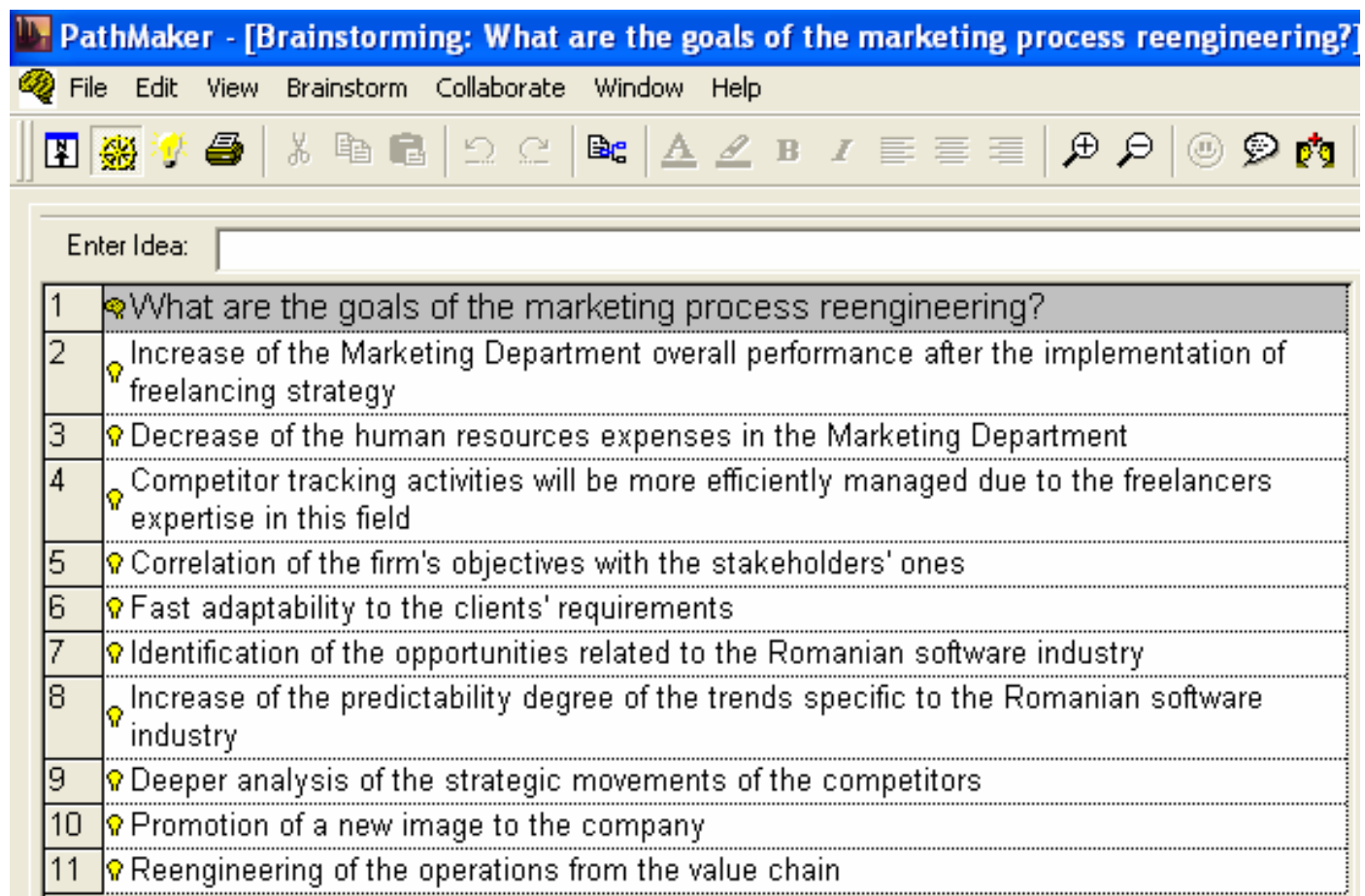

Figure 2. Application of the Brainstorming Tool in the marketing process reengineering within the software company. 


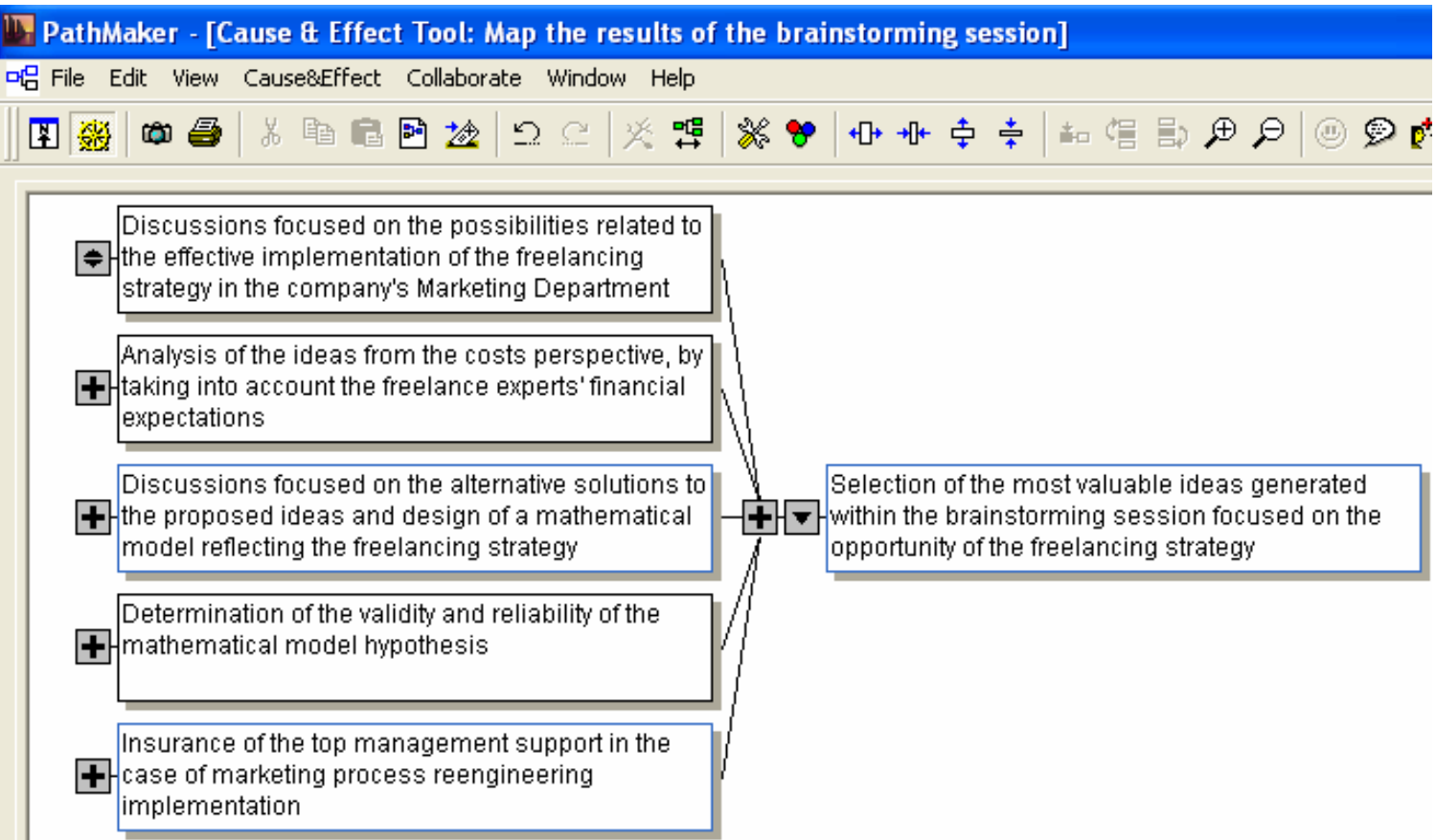

Figure 3. Application of the Cause \& Effect Tool in the marketing process reengineering within the software company.



Figure 4. Application of the Force Field Tool in the marketing process reengineering within the software company.

\section{Conclusions, Limitations and Further Research Agenda}

Future trends in HR management could bring permanent changes on the workforce market. Thus, employers are going to rely more and more on external expertise, based on fixed-period contract workforce, such as temporary employees or freelancers, in order to reach business ob- jectives in a strategic manner.

In our case study developed on the Romanian software company, marketing process reengineering could be reached through an efficient change management, in which innovative HR solutions such as freelancing must be taken into account. As the mathematical modelling and the use of specific software support the decision- 
making processes, we remark the impact of these tools on the outcomes of our research.

The outcomes of the marketing reengineering process will determine the improvement of the competitive position of the software company, as a result of the valuable expertise of the freelancers in the Competitor Tracking area.

Although the software company where we developed the case study is representative for this sector, the findings are limited to one company. It is a local specific context without international comparisons, by taking into consideration different companies from this industry.

A future research will be focused on the design of key performance indicators for this company, integrated in a Balanced Scorecard system, which allow the performance assessment for each perspective: financial, customer, internal process, learning and innovation. Thus, the effects of the marketing process reengineering will be analyzed through a multidimensional perspective.

\section{Acknowledgements}

This work was co-financed from the European Social Fund through Sectoral Operational Programme Human Resources Development 2007-2013, project number PO$\mathrm{SDRU} / 1.5 / \mathrm{S} / 59184$, performance and excellence in postdoctoral research in Romanian economics science domain.

\section{REFERENCES}

[1] J. Storey, G. Salaman and K. Platman, "Living with Enterprise in an Enterprise Economy: Freelance and Contract Workers in the Media," Human Relations, Vol. 58 No. 8, 2005, pp. 1033-1054. doi: $10.1177 / 0018726705058502$
[2] M. C. Lacity, L. P. Willcocks and J. W. Rottman, "Global Outsourcing of Back Office Services: Lessons, Trends, and Enduring Challenges," Strategic Outsourcing, Vol. 1, No. 1, 2008, pp. 13-34.

[3] S. Vincent, "The Moral Mazes of the New Economy: The Clique Politics of Freelance HR Consultants," Proceedings of the 7th International Critical Management Studies Conference, Naples, 11-13 July 2011.

[4] A. Walker-Fraser, "Coaching and the Link to Organizational Performance: An HR Perspective on How to Demonstrate Return on Investment," Development and Learning in Organizations, Vol. 25, No. 4, 2011, pp. 8-10. doi:10.1108/14777281111147035

[5] J. E. Lynch, "Marketing and Business Process Reengineering," Journal of Marketing Practice: Applied Marketing Science, Vol. 1, No. 1, 1995, pp. 45-53. doi:10.1108/EUM0000000003879

[6] S. C. Gardiner, J. B. Hanna and M. S. La Tour, "ERP and the Reengineering of Industrial Marketing Processes. A Prescriptive Overview for the New-Age Marketing Manager," Industrial Marketing Management, Vol. 31, No. 4, 2002, pp. 357-365. doi:10.1016/S0019-8501(01)00167-5

[7] M. Attaran, "Exploring the Relationship between Information Technology and Business Process Reengineering," Information \& Management, Vol. 41, No. 5, 2004, pp. 585-596. doi:10.1016/S0378-7206(03)00098-3

[8] R. C. Lee, "Does the Success of Information Systems Really Matters to Firm Performance?" iBusiness, Vol. 4, No. 2, 2012, pp. 98-107.

[9] S. Hao and B. Yu, "The Impact of Technology Selection on Innovation Success and Organizational Performance," iBusiness, Vol. 3, No. 4, 2011, pp. 366-371.

[10] X. Zha and M. Chen, "Competitive Intelligence Monitoring in the Risk Prevention of SMEs," Journal of Service Science and Management, Vol. 3, 2009, pp. 230-235. doi:10.4236/jssm.2009.23028 